\title{
Low Cardiac Output
}

National Cancer Institute

\section{Source}

National Cancer Institute. Low Cardiac Output. NCI Thesaurus. Code C50641.

A below normal volume of blood pumped from the right or left ventricle of the heart per unit time. 